\title{
NANOPHTHALMOS WITH UVEAL EFFUSION
}

\author{
HISAHARU YOSHIOKA, TAKASHI SUGITA AND MOTOAKI RYU \\ Department of Ophthalmology, Kurume University School \\ of Medicine, Kurume, 830, Japan
}

(Received for publication November 25, 1976)

\begin{abstract}
A 52-year-old woman presented all ocular and systemic findings of the spontaneously occurred uveal effusion described by Schepens and Brockhurst associated with microphthalmos and high degrees of hyperopia was reported. Fluorescein angiography revealed the presence of profound leakages from the choroid into subretinal spaces at the posterior and equatorial region, and the presence of focal leakages in some central retinal veins of the right eye. Left eye showed numerous fluorescent dots due to pigment epithelial defects of the posterior pole and of the equatorial region. It was thus suggested that uveal effusion described by Schepens and Brockhurst may be the same disease as bullous retinal detachment (Gass, 1973), peculiar type of secondary retinal detachment (Tsukahara, 1973), characteristic chorioretinal lesion with peripheral retinal detachment (Mimura et al, 1973), or effusive central serous choroidoretinopathy (Yoshioka, 1973) in Japan.
\end{abstract}

\section{INTRODUCTION}

In pure microphthalmos or nanophthalmos, the eye is small in its overall dimensions but is not affected by other gross developmental defects not accompanied by other systemic developmental defects. Nanophthalmos with secondary retinal detachment has already been reported by several authors, but the pathogenesis of those secondary retinal detachment is still unknown.

Recently Tohma et al. (1975) reported two cases of pure microphthalmos associated with marked hyperopia and non-rhegmatogenous retinal detachment. With fluorescein angiography in two cases, multiple foci of the fluorescein leakages from the choroid into subretinal spaces has been demonstrated only in one case. They postulated the possibility of presence of two kinds of secondary retinal detachment in patient with nanophthalmos.

In 1975, Brockhurst reported on the five patients exhibited uveal effusion after glaucoma surgery in patients with nanophthalmos but he could not demonstrate any fluorescent leakage in one case examined with fluorescein angiography.

The purpose of this report is to demonstrate a case with spontaneously occurred uveal effusion described by Schepens and Brockhurst in high degrees of hyperopic eye with nanophthalmos.

\section{CASE REPORT}

A 52-year-old housewife was visited to our hospital, March, 27, 1976, with the complaint of the diminution of visual acuity of both eyes. 
At February 27, 1976, she was suddenly aware of black membranous shadow at the upper side of the visual field and metamorphopsia in the right eye. She had been non-treated and 20 days after onset, noted black shadow which expanded to lower and nasal side of the visual field in the right eye. Visual acuity of the left eye had been also gradually diminished since the onset, but she did not complain subjectively the defect of the visual field.

At March, 16, 1976, she visited other clinic of ophthalmology, and was treated under the diagnosis of bilateral optic neuritis with the administration of betamethasone, systemically and subconjunctivally, and oral administration of vit. B12. But ocular symptoms were not improved and diminution of visual acuity in both eyes were gradually aggravated, so she was refered to our department of ophthalmology.

Past History: Patient had poor visual acuity by nature and marked hyperopia.

Family History: No consanguiness

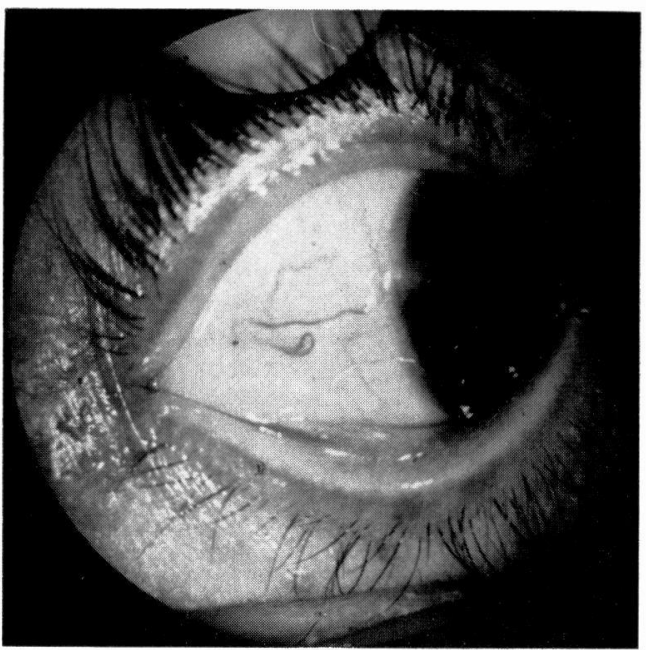

Fig. 1 Right eye : dilated and distorted vessels of the conjunctiva bulbi according to the palpebral fissure. marriage, and there was no history of hyperopia in her family tree.

Initial findings of ophthalmologic examination

Her eyes were bilaterally enophthalmic and the exophthalmometer reading was $9 \mathrm{~mm}$ right and $8 \mathrm{~mm}$ left on a base of $90 \mathrm{~mm}$ by Hertel.

The eyeball situation and movement was normal. The right visual acuity was hand movement at $20 \mathrm{~cm}$ and the left was $+13 \mathrm{D}$ sph. $=0.04$.

The intraocular pressure was 15.88 $\mathrm{mmHg}$ in right eye and $13.35 \mathrm{mmHg}$ in left eye.

According to the palpebral fissure, blood-vessel of bulbar conjunctiva on the both sides of the cornea was dilated and distorted, but there were not seen conjunctival and ciliary injection (Fig. 1).

\section{Slitlamp examination}

The depth of peripheral and central

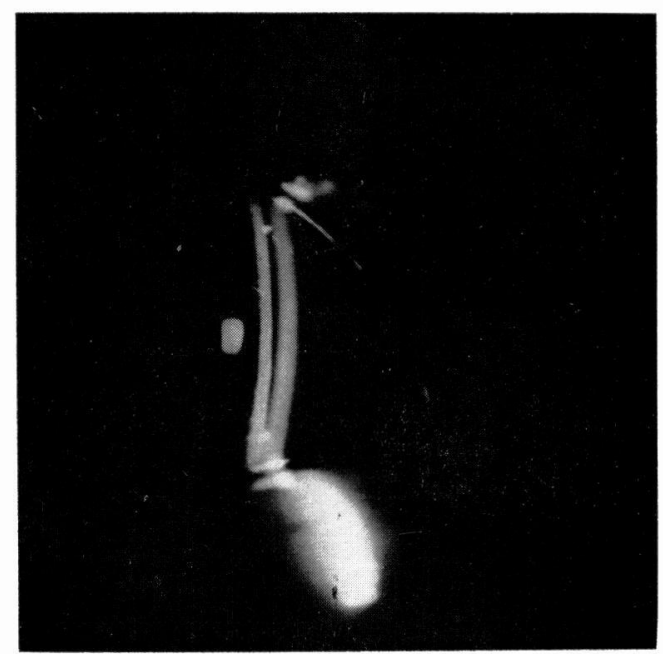

Fig. 2 Right eye : shallow anterior chamber at the slit lamp examination. 
anterior chamber of both eyes was markedly shallow and those of the right chamber was more shallow than the left one (Fig. 2).

No aqueous flare and cells were seen. The anterior chamber angle showed
Grade III by scheie's classification and was only seen at the anterior one-third part of trabeculum. There was no peripheral anterior synechia and congenital malformations at the angle.

The flare of vitreous body was observed but no cell was seen.
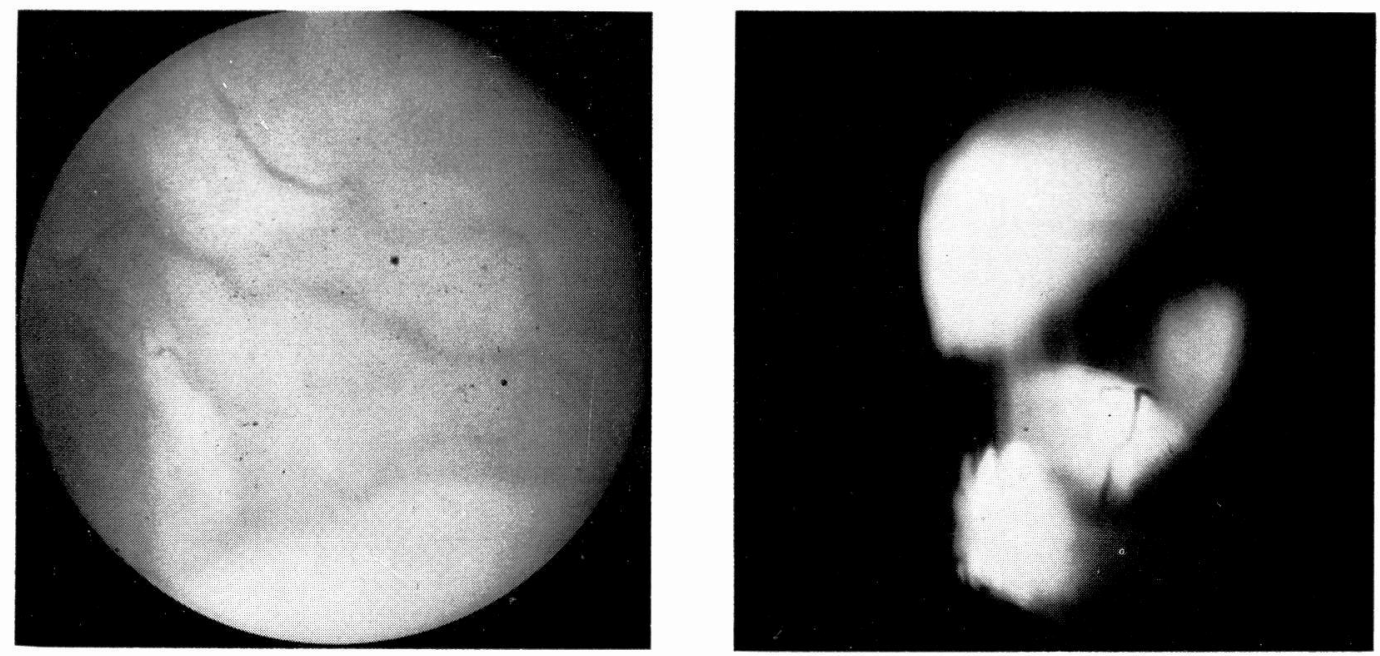

Figs. 3 and 4 Right eye: Ophthalmoscopic finding (Fig. 3) and slit-lamp examination (Fig. 4) in initial examination. Retina was bullously detached at the bellow and temporal region and the detached retina was reached straight behind the lens.

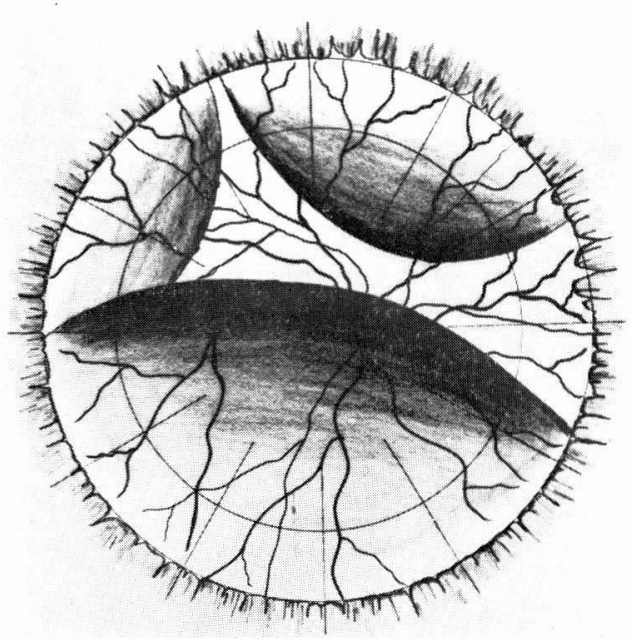

Fig. 5 Schema of the right fundus.

\section{Ophthalmoscopical examination}

Ophthalmoscopical examination of the right eye showed that the optic disc was covered by prominent bullous detached retina, and so wasn't well observed. Retinal vessels, both artery and vein, on the surface of the detached retina were remarkably tortuous and dilated. Retina was entirely detached, especially bullously detached at the bellow and temporal region of the optic disc (Fig. 3), and the detached retina was reached straight behind the lens (Fig. 4).

Two small dot haemorrhages were seen at 5 disc diameter temporal inferior from the macula. Choroidal de- 
tachment was seen at periphery except for nasal region. Any tear wasn't found in the detached retina. Subretinal fluid was easily moved by changing position (Fig. 5).

The optic disc of the left eye was slightly swelled and the margin was unclear. Retinal artery and vein were tortuous and dilated from posterior pole to ora serrata. Foveal reflex was ab-

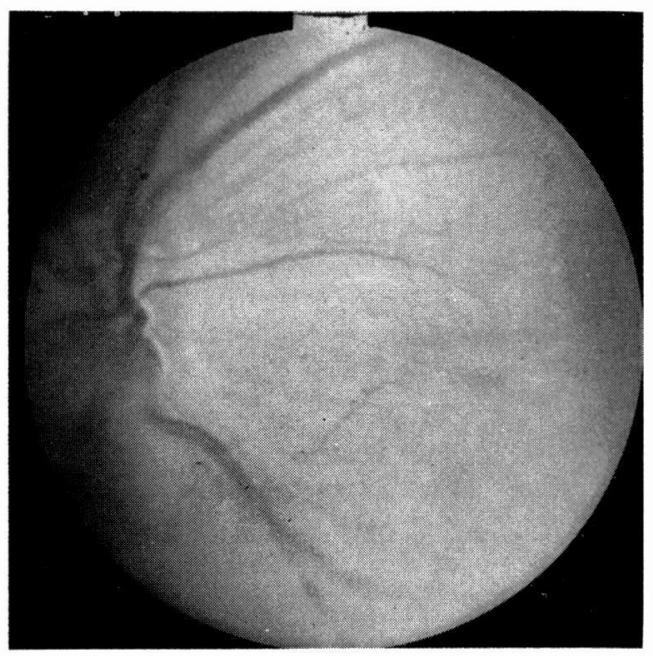

Fig. 6 Left eye of initial examination : The optic disc was slightly swelled and flat detachment was seen accompaning with retinal radial wrinkle around the macula.

\section{Visual field examination}

Goldmann perimetry with $\mathrm{V}_{4}$ target showed narrowing at the superior and temporal area of the visual field on the right eye (Fig. 8).

The visual field of the left eye was depressed at the superior area, where the retinal detachment was observed, when the II 4 target was used (Fig. 9).

\section{Colour vision examination by Panel} D-15 sent and flat retinal detachment was seen accompaning with retinal radial wrinkles around the macula (Fig. 6). This detachment was extended to temporal inferior from the macula in fanlike shape. There were many scattering drusen like hard exudates at the area of detached retina (Fig. 7). Ora serrata was easily observed totally surrounding without ocular pressing.

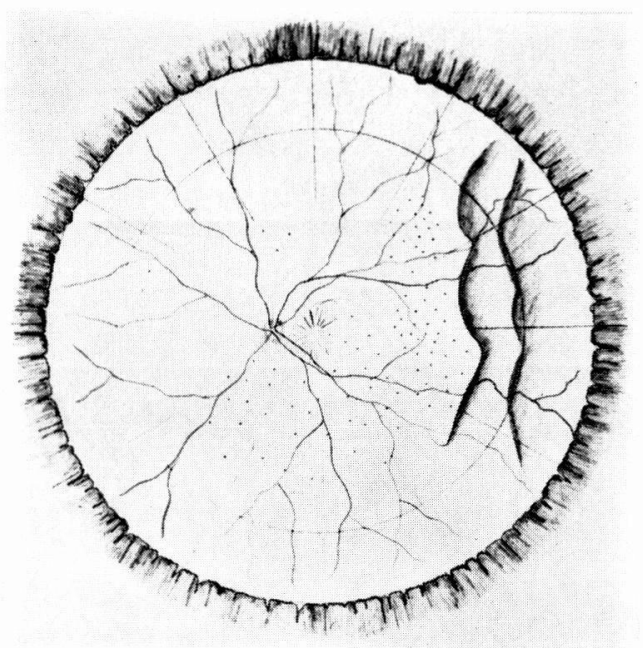

Fig. 7 Schema of the left fundus.

The colour vision of the both eyes was uncertain axis.

\section{Electroretinographic examination}

The $b$-wave and oscillatory potential was decreased and "subnormal" in the both eyes and those findings of ERG in the right eye was more decreased than those of the left.

\section{Ultrasonic examination}

General's ZD-251 type ophthalmic 


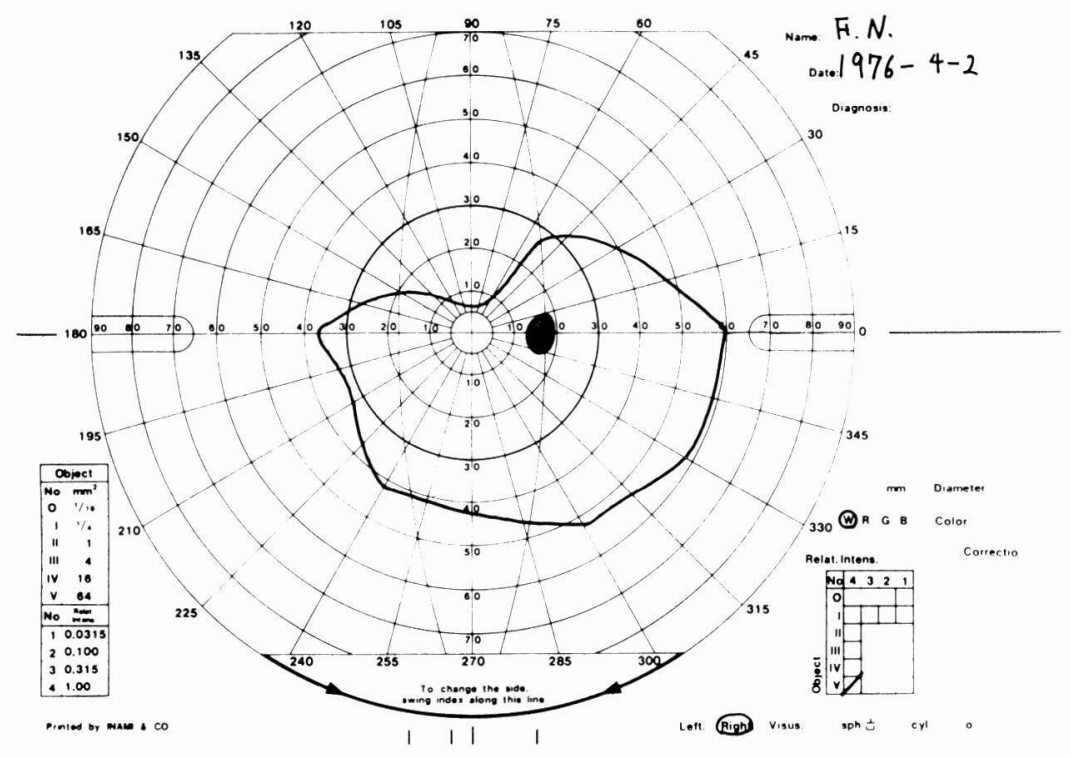

Fig. 8 The visual field of the right eye: Goldmann perimetry with $\mathrm{V}_{4}$ target showed narrowing at the superior and temporal area of the visual field on the right eye.

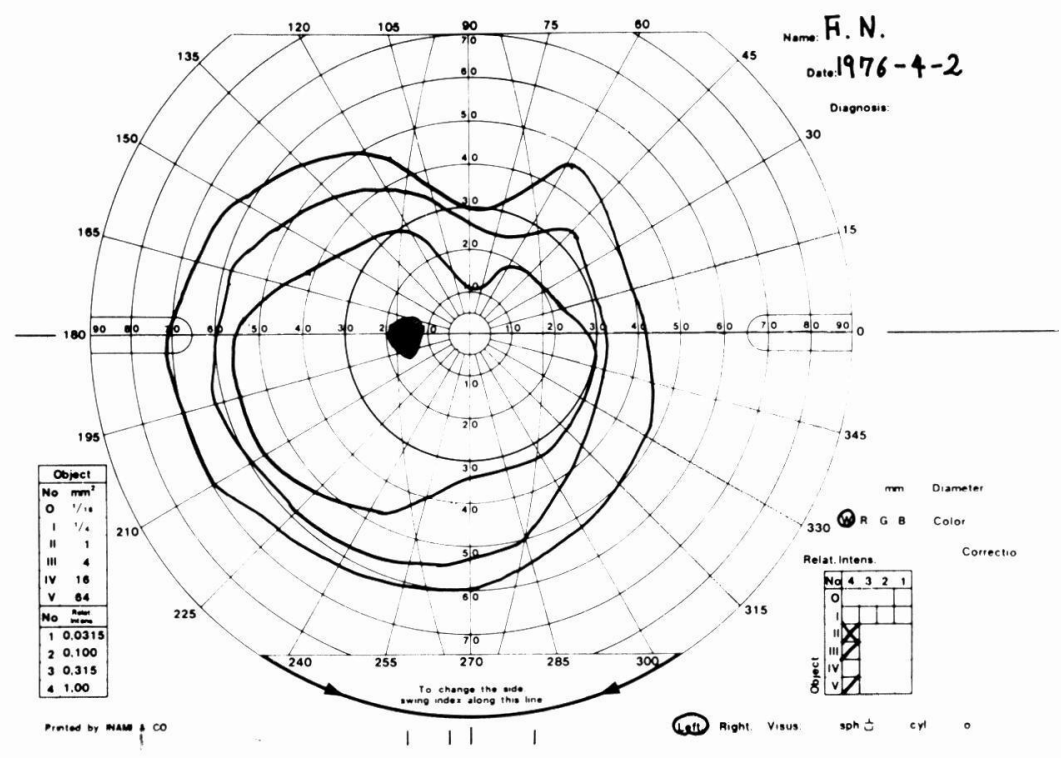

Fig. 9 The visual field of the left eye: The visual field of the left eye was depressed at the superior area, where the retinal detachment was observed, when the $\mathrm{V}_{4}$ target was used. 


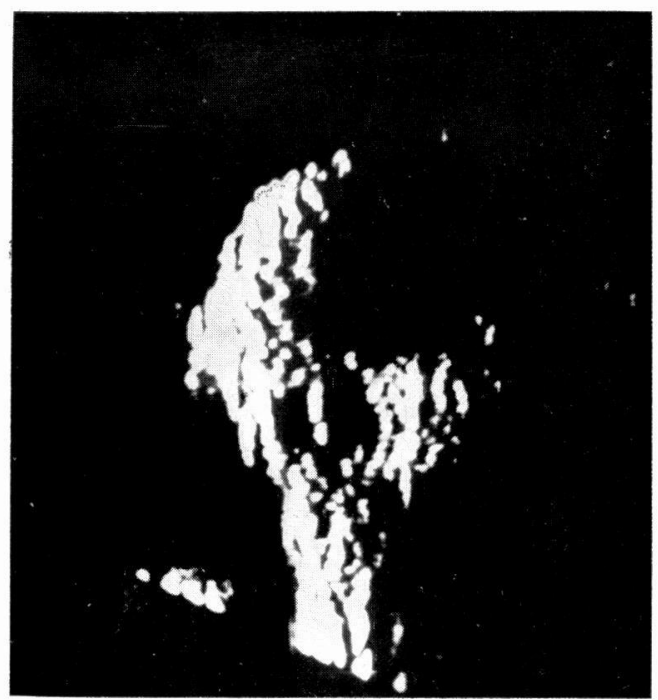

Fig. 10 B-scan ultrasonic echogram.

ultrasound head of lithium sulfate $(\mathrm{LH})$ were used and A- and B-scan ocular ultrasonography was performed (Figs. 10 and 11).

The anterior chamber of the right eye was $1.78 \mathrm{~mm}$ in depth and the left was $1.89 \mathrm{~mm}$ and the depth in this case was less than a half in the normal case. The lens of the right eye was $5.64 \mathrm{~mm}$ in length and the left was $5.98 \mathrm{~mm}$. The lens in this case was more thickened than in the normal case. The sclera was also more thickened than the normal sclera, bilaterally.

The anterior posterior axial length of the right eye was $15.97 \mathrm{~mm}$ and the left was $15.59 \mathrm{~mm}$ and was less than two-third of the normal eye.

\section{Systemic examination}

R.B.C. was $438 \times 10^{4}$, W.B.C. was 4100 and the erythrocyte sedimentation rate was $4 \mathrm{~mm} / \mathrm{hr}$. .

Serologic test for syphilis was negative. Toxoplasma hemagglutination was also negative. Liver and renal func-

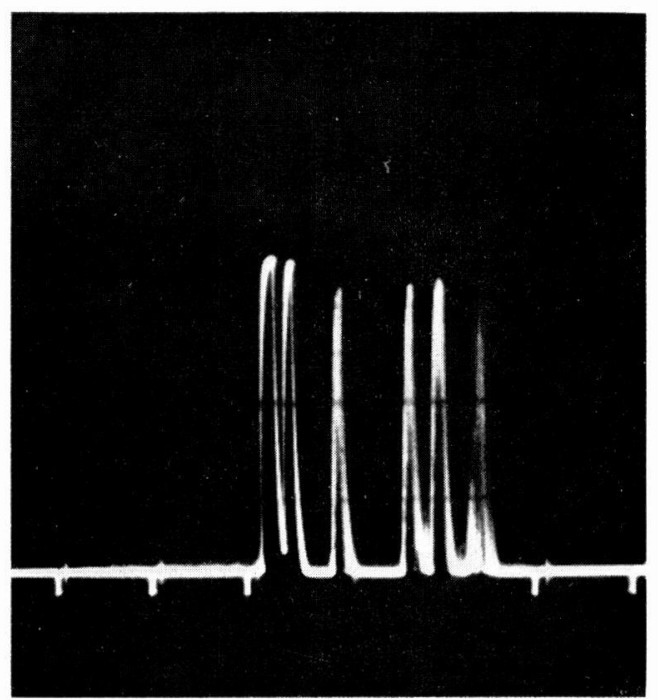

Fig. 11 A-scan ultrasonic echogram.

tion test was normal. Serum total protein and electropholetic pattern of it was normal. Serum $\mathrm{Na}^{+}$was $141 \mathrm{mEq} / 1$ and $\mathrm{K}^{+}$was $4.5 \mathrm{mEq} / 1, \mathrm{Cl}^{-}$was $117 \mathrm{mEq} / \mathrm{l}$. ASLO was 125 unit. R-A test and Creactive protein were negative. B. M. R. was $-17 \%, \mathrm{~T}_{3}$ was $27.7 \%$ and $\mathrm{T}_{4}$ was $63 \mu \mathrm{g} / \mathrm{dl}$.

Chest X-ray and electrocardiogram showed no abnormality. The findings in cerebrospinal fluid was showed at Table 1.

She had no sings of dysacousia, alopecia, poliosis and vitiligo. She had also no malformations.

TABLE 1

Findings in cerebrospinal fluid

$\begin{array}{lc}\text { Initial pressure } & 140 \mathrm{mmH}_{2} \\ \text { Appearance } & \text { watery, co } \\ & \text { and clear } \\ \text { Cell } & 3 / 3 \\ \text { Total protein } & 60 \mathrm{mg} / \mathrm{dl} \\ \text { Sugar } & 76 \mathrm{mg} / \mathrm{dl} \\ \text { Cl } & 129 \mathrm{mEq} / \mathrm{l}\end{array}$


One month after the onset, she was hospitalized and $1 \%$ atropin was given on both eyes and kept quiet.

Forty-five days after the onset, she was treated with subconjunctival injection of betamethasone on the right eye.

Two months after the onset, the right visual acuity was $+16 \mathrm{D}$ sph. $=0.04$ and the left was +13D sph. $=0.04$.

Ophthalmoscopically, choroidal detachment on both eye was spontaneously resolved. Retinal detachment on right eye was disappeared at the upper and nasal part of the optic disc and was also become flat at the inferior to the macula, but bullous detachment was still seen from inferior equatorial region to the periphery (Fig. 12). Dot haemorrhages which had been observed at the temporal inferior portion of the macula was disappeared. Retinal detachment of the left eye was resolved, and retina was becoming slightly reddish. Foveal reflex was any more absent. Retinal radial wrinkles were seen around the macular region. Many hard white spots and gross pigment migration were seen at the temporal side of the macula (Fig. 13).

Fluorescein fundus findings - Cho-
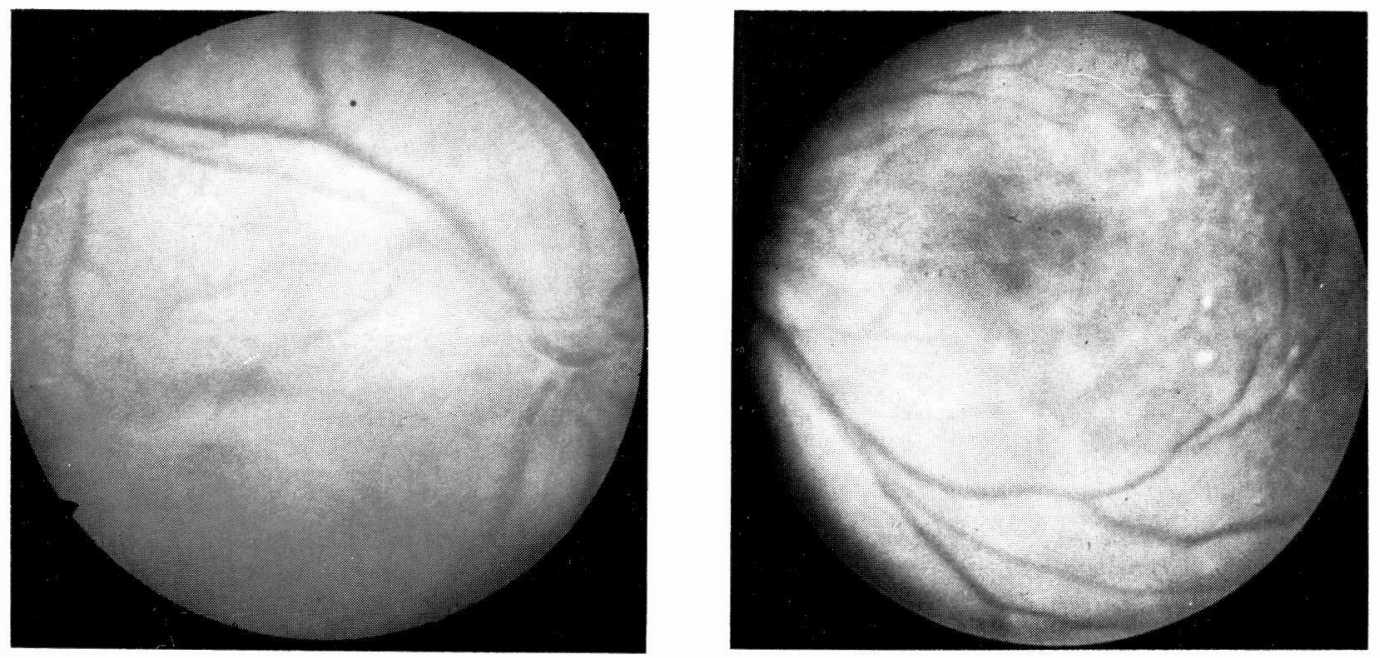

Figs. 12 and 13 Forty five days after the onset (Fig. 12) Right eye: Retinal detachment was disappeared at the upper and nasal part from the optic disc and also become flat at the inferior to the macula. (Fig. 13) Left eye: Retinal detachment was resolved and retinal radial wrinkles were seen around the macular region. Many hard white spots and gross pigment migration were seen at the temporal side of the macula.

roidal background fluorescence of the right eye was seen as wide spread pigmentary mottling in arterial phase (Fig. 14). There was fluorescent halo around the optic disc, and gradual leakage of the dye from the circumference of the halo with time. Choroidal fluorescence was increased with time and local leakage of fluorescein was seen at the one disc diameter superiotemporal area of the macula (Fig. 15) at the same time, there was marked leakage of the dye from the choroid into subretinal space at the inferior 
equatorial region (Fig. 16) and also from the retinal vessel at the temporal inferior area of the optic disc
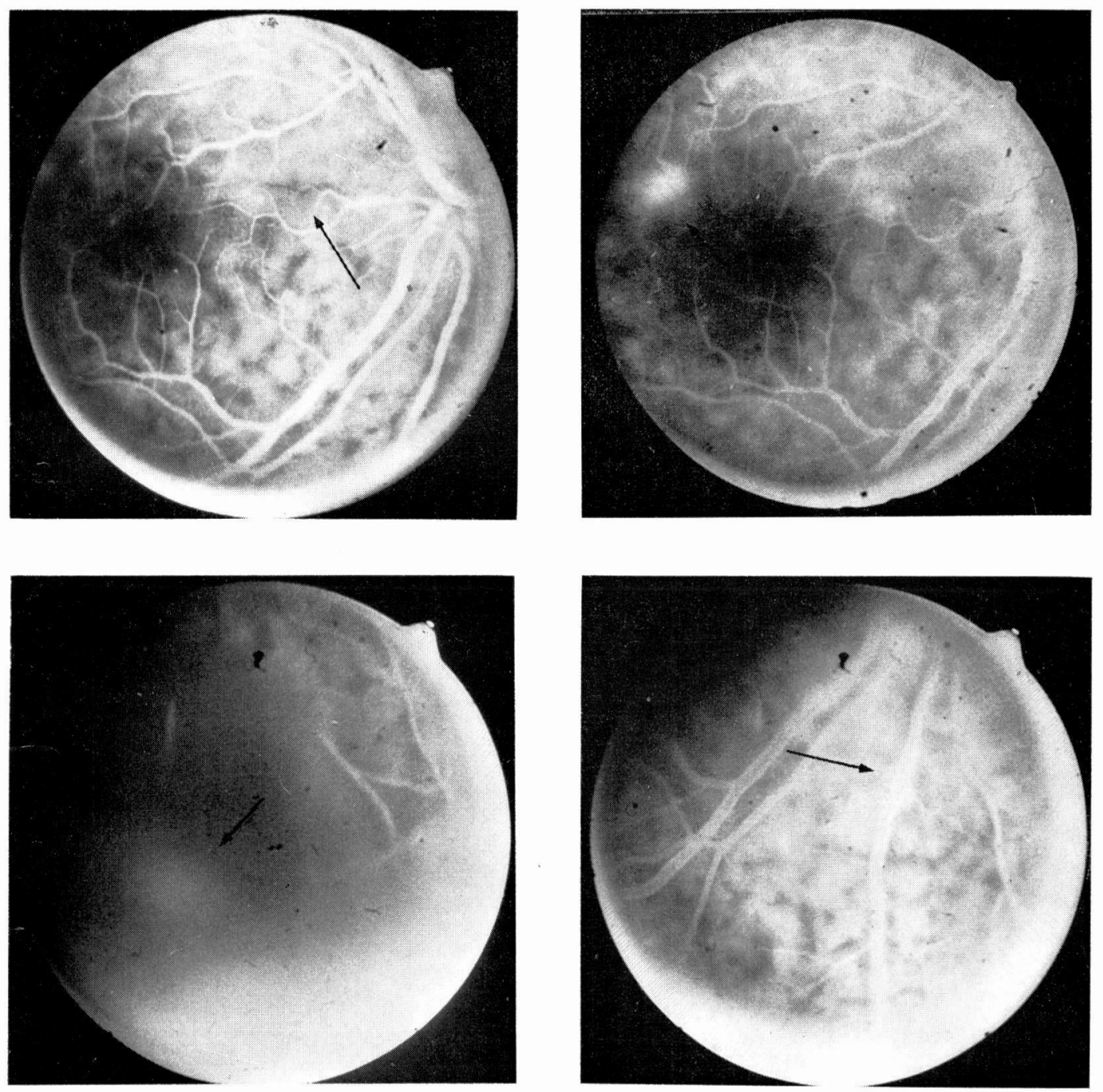

Figs. 14-17 Fluorescein angiographic findings of the right eye:

(Fig. 14) Choroidal background fluorescence was observed as widespread pigmentary mottling in arterial phase. There was defect of narrow strip between the optic disc and the macula (arrow).

(Fig. 15) Choroidal fluorescence was increased with time and 1ocal subretinal leakage of fluorescein was seen at the one dise diameter superior-temporal area of the macula.

(Fig. 16) At the inferior midperiphery of the optic disc.

(Fig. 17) At the time, fluorescein leakage of the dye from the retinal vessel was seen at the temporal inferior area (arrow). 


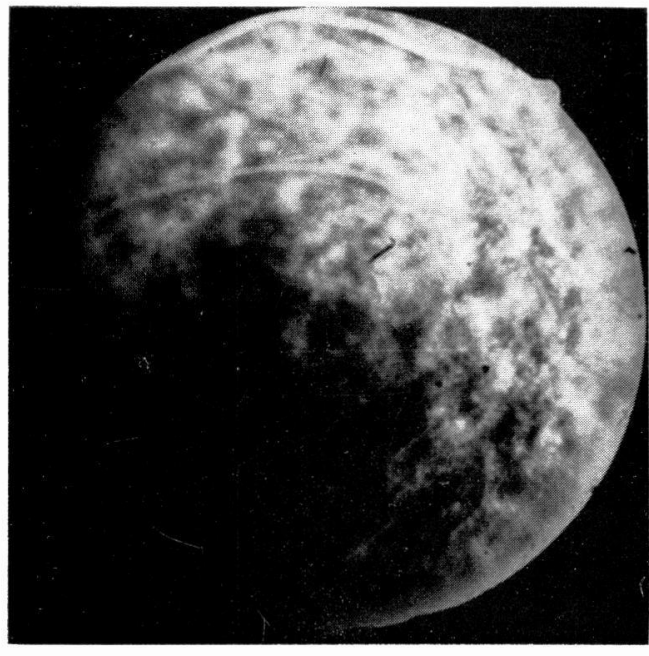

Figs. 18 and 19

(Fig. 18) Choroidal mottling fluorescence was seen in arterial phase, but there was not leakage of the dye in contrast the findings of the right eye.

and which was gradually increased in intensity while late venous phase, but there was no leakage of the dye from the choroid into subretinal spaces in contrast the finding of the right eye (Fig. 18). There was fluorescent halo around the optic disc and slightly leakage of the dye from the halo with time (Fig. 19).

The colour vision of the right eye was showed the form of uncertain axis as the initial examination by Panel D15 , but the left was showed the form of Tritan.

The visual field of the left eye had been widened at the superior portion.

Three months after the onset, Ruby laser photocoagulation was performed to the region of the fluorescein leakage at the temporal superior area of the macula. Two shots, which was small spot size and $1.2 \mathrm{Kv}$ power level, were performed.

Seven days after Ruby laser photo-

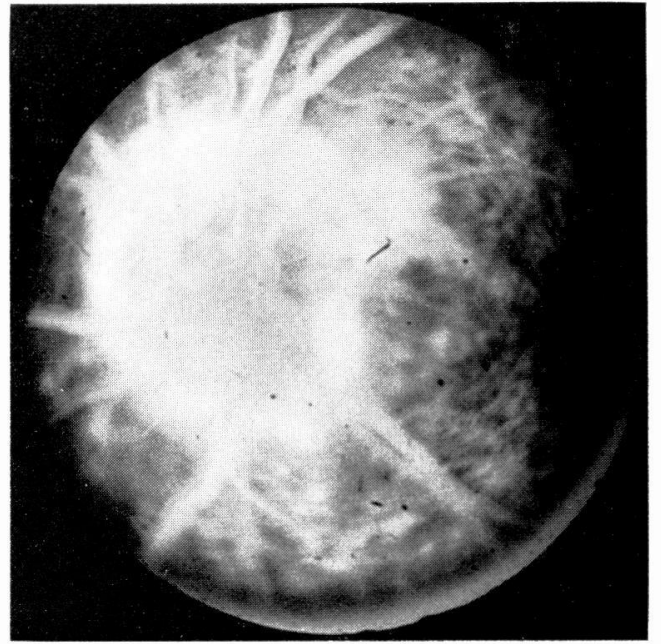

Left eye :

(Fig. 19) There was fluorescent halo around the optic disc and slightly leakage of the dye from the halo with time.

coagulation in ophthalmoscopic examination of the right eye, the optic disc was still slightly swollen, but the tortuosity of the retinal vessel was disappeared (Fig. 20). Previously observed retinal detachment was almost disappeared but bullous detachment was still remained inferior periphery at the 4 to 5 disc diameter of the optic disc.

Fluorescein angiographic findings in the right eye-Focal subretinal leakage at the temporal inferior area of the macula was disappeared, but leakage at the inferior midperiphery of the optic dise was still remained which was fulfilled under the detached retina.

In opthalmoscopical examination of the left eye, the optic disc showed normal appearance and the margin became cleary recognized (Fig. 21).

Retinal radial wrinkles and many drusen like hard exudates were seen around the macula, but retinal detach ment was disappeared completely. 

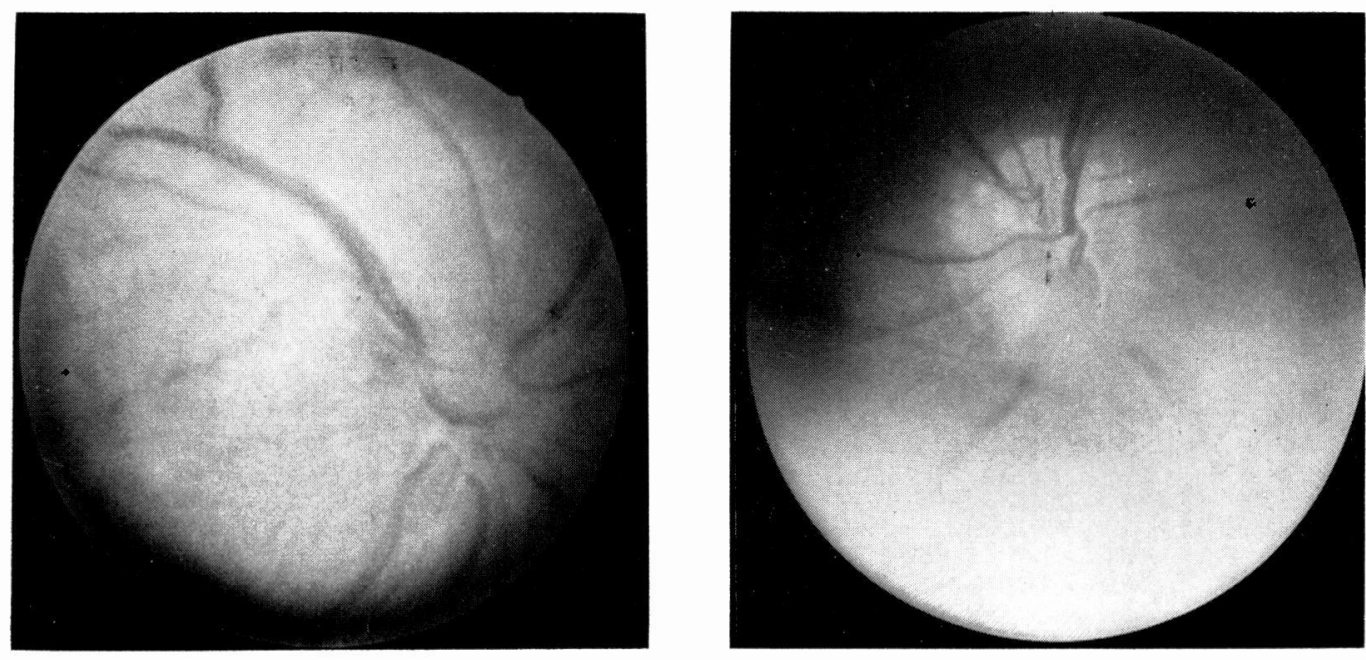

Figs. 20 and 21 Three months after the onset

(Fig. 20) Ophthalmoscopic examination of the right eye, the optic disc was still slightly swelled, but previously observed retinal detachment was almost disappeared.

\section{DICUSSION}

Uveal effusion described by Schepens and Brockhurst affects most often middle-aged subjects and almost exclusively males. The onset is insidious, and eye signs are characterized by a slowly progressive and of ten bilateral retinal detachment with shifting subretinal fluid and without retinal breaks. A flat choroidal detachment is frequently present in the fundus periphery; edema of the optic disc is not rare. Signs of uveitis are either minimal or absent. The course of the disease is slowly progressive and of ten similar but not necessarily simultaneous in both eyes. After months or even several years, reattachment of the retina may occur either with or without treatment. Associated systemic disturbances are elevated pressure and increased protein with pleocytosis in the cerebrospinal fluid.
(Fig. 21) The optic disc of the left eye showed normal appearance. Drusen at the optic disc become more clearly recognized.

The case described here in which fulfilled the all of these clinical findings accords with the uveal effusion.

On the other hand, there are some reports on the secondary retinal detachment initiated with focal retinal exudates in the posterior pole; i. e. bullous retinal detachment (Gass, 1973), peculiar type of secondary retinal detachment (Tsukahara, 1973), characteristic chorioretinal lesion with peripheral retinal detachment (Mimura et al., 1973), or effusive central serous chorioretinopathy (Yoshioka, 1973).

This condition affects predominantly middle age subjects, more in males, and is characterized by the acute onset, moderate decrease of visual acuity, localized retinal detachment with retinal exudates in the posterior pole, and radiating folds at the macular region. These retinal detachment in the posterior pole extends to the inferior periphery with shifting fluid and no retinal 
breaks. Rarely choroidal detachment may occur at the fundus periphery. Some retinal haemorrhages or punctate exudates along the retinal arteries may be seen in the areas of the previously detached retina during the course of this condition. In the protracted case the subretinal scar formation may also be seen at the macular region. All cases of this condition do not reveal any beneficial effect to the steroid therapy. No positive results are obtained by various systemic examinations. Fluorescein angiography demonstrates the leaking spots in the area corresponding to the retinal exudates at the posterior pole from choroid into subretinal spaces.

One of us (Yoshioka, 1976) had reported a healthy 42-year-old man with uveal effusion of the left eye. This case showed typical secondary retinal detachment with shifting fluid, retinal exudates in the posterior pole, annular choroidal detachments, shallow anterior chamber, marked hypotony, and transient myopia except for findings of cerebrospinal fluid. Angiograghic findings revealed numerous spots leaking from choroid into subretinal spaces not only in the posterior pole but also in the temporal and inferior equatorial regions.

Even in patients with uveal effusion described by Schepens and Brockhurst, the facts that in a few cases the exudates in the subretinal cavity formed strands or irregular membranes, which were attached to the detached retina on one side and to the pigment epithelium on the other, one case showed transitory yellow periarterial exudates in the detached portion of the retina, and the presence of retinal exudates with radial folds and scar formation at the macular region has been illustrated in the figures of a case with uveal effusion by Brockhurst, may be strongly suggested that in patients with uveal effusion reported by Schepens and Brockhurst there are two types of secondary retinal detachment, one is those initiated with retinal exudates at the posterior pole and the other is those secondary to spontaneous ciliochoroidal detachment.

Considering of the differences of the funduscopic and fluorescein angiographic findings in both eyes of our typical case of the uveal effusion, the evidences which in the right eye the profound fluorescein leakages from the choroid into subretinal spaces despite the absence of retinal exudates were demonstrated at the posterior and inferior equatorial regions, and some retinal haemorrhages with focal fluorescein leakages of the retinal vein as seen in the bullous retinal detachment, special type of secondary retinal detachment, or effusive central serous choroidoretinopathy were found in the previously detached retina may be strongly suggested that latter condition also closely resembles to the clinical signs of uveal effusion.

Thus we would like to postulate that both conditions may be same disease and the clinical signs of both conditions may only be different from the difference of initial site of the lesion. The uveal effusion may therefore be classified as 1) posterior pole type (those initiated with retinal exudates at the posterior pole, i. e. bullous retinal detachment, special type of secondary retinal detachment, or effusive central serous choroidoretinopathy), 2) equatorial type (those initiated with spontaneous ciliochoroidal detachment), and 3) mixed type.

\section{REFERENCES}

BRockhurst, R. J. and LAM, K. W. (1973). Uveal effusion II. Report of a case with analysis of subretinal fluid. Arch. Ophthal., 90, 399-401. 
BROCKHURST, R.J. (1974). Nanophthalmos with uveal effusion. A new clinical entity. Trans. Amer. Ophthal. Soc., 72, 371-403.

BROCKHURST, R.J. (1975). Nanophthalmos with uveal effusion. A new clinical entity.

Arch. Ophthal., 93, 1289-1299.

GASs, J. D. M. (1973). Bullous retinal detachment. An unusual manifestation of idiopathic central serous choroidopathy. Amer. J. Ophthal., 75, 810-821.

Mimura, Y, Yuasa,T., Tohma,N., Moriyama, H. and HoHкI, T. (1973 a). Studies on the characteristic chorioretinal lesion with peripheral retinal detachment. Folia Ophthal. Jap., 24, 130-136.

Mimura, Y, Hohki, T., Yuasa, T., Tohma, N. and Moriy AMA, H. (1973b). Retinochoroidal affection associated with peripheral retinal detachment. Part II. Pathogenesis and differential diagnosis. Jap. J. Clin. Ophth. 27, 39-44.

Schepens, C. L. and Brockhurst, R. J. (1963). Uveal effusion I. Clinical picture. Arch.
Ophthal., 70, 189-201.

Tohma, N., Matsumoto, K. and Ichinashi, K. (1975). Two cases of pure microphthalmia with high hyperopia and non-rhegmatogenous retinal detachment. Folia Ophthal. Jap., 26, 866-873.

Tsukahara, I. (1973). A peculiar type of secondary detachment of the retina. With special reference to central serous choroidopathy and peripheral uveitis. Jap. J. Clin. Ophth., 27, 1003-1008.

Tsukahara, I. (1974). New type of secondary detachment of the retina with special reference to central serous choroidopathy. Jap. J. Clin. Ophth., 28, 97-105.

Yosнioka, H. (1973). Effusive central serous choroidoretinopathy. Essays in Commemoration of the Retirement of Professor Y. Masuda., 262-279.

YosHIOKA, H. (1976). Fluorescein angiographic findings in the uveal effusion. Folia Ophthal. Jap., 27, 836-844. 